\title{
Dual orexin receptor antagonists for insomnia in youth with neurodevelopmental disorders: a case series and review
}

\author{
Aaron D. Besterman ${ }^{1,2,3,4}$ (D) Shafali S. Jeste $e^{4,5,6,7}$ (D)
}

Received: 29 June 2021 / Accepted: 23 September 2021 / Published online: 5 October 2021

(c) The Author(s) 2021

\begin{abstract}
Insomnia is a common, impairing, and difficult-to-treat comorbidity in children with neurodevelopmental disorders (NDDs). Behavioral interventions can be challenging because of developmental and behavioral features that interfere with treatment. Medication management also can be difficult due to a high burden of side effects, a high rate of paradoxical responses, and frequent treatment resistance. Therefore, new treatment options for insomnia in children with NDDs are needed. Dual orexin receptor antagonists (DORAs) are a relatively new class of pharmacotherapeutics that induce sleep by inhibiting the orexin signaling pathway. To date, there is little safety or efficacy data on the use of DORAs in children with NDDs. We present four patients with NDDs and insomnia that we treated with the DORA, suvorexant. We found that patients had a wide range of responses, with one patient displaying a robust improvement in sleep onset and maintenance, while another had significant improvement in insomnia symptoms on combination therapy with trazodone. Our final two patients had mild or no benefit from suvorexant therapy. Further research is necessary to establish the safety and efficacy of DORAs in this population and to identify predictive factors, such as specific neurogenetic diagnoses or clinical features, of a positive treatment response.
\end{abstract}

Keywords Insomnia $\cdot$ Neurodevelopmental disorders $\cdot$ Dual orexin receptor antagonists $\cdot$ Sleep disorders

\section{Introduction}

Sleep disorders are common in patients with neurodevelopmental disorders (NDDs), such as global developmental delay (GDD), autism spectrum disorders (ASD) and intellectual disability (ID) [1]. While prevalence estimates vary depending on how sleep disorders are defined and on the specific group of patients studied, sleep problems in patients with NDDs are linked to negative functional outcomes, such as daytime sleepiness, worsening cognitive function, irritability, and challenging behavior [1]. A diagnosis of insomnia requires (1) a report of sleep initiation or maintenance problems, (2) adequate opportunity and circumstances to sleep, and (3) daytime consequences [2]. Behavioral interventions are first-line treatments for insomnia, such as improving the child's sleep environment or creating a more regular bedtime routine [3, 4]. However, behavioral comorbidities associated with NDDs, such as hyperactivity, irritability or insistence on sameness, can limit the effectiveness of behavioral interventions making pharmacotherapies necessary.

Melatonin has the most robust safety and efficacy data for insomnia in patients with NDDs [5], but there are additional pharmacotherapy options (Table 1). Patients with NDDs 


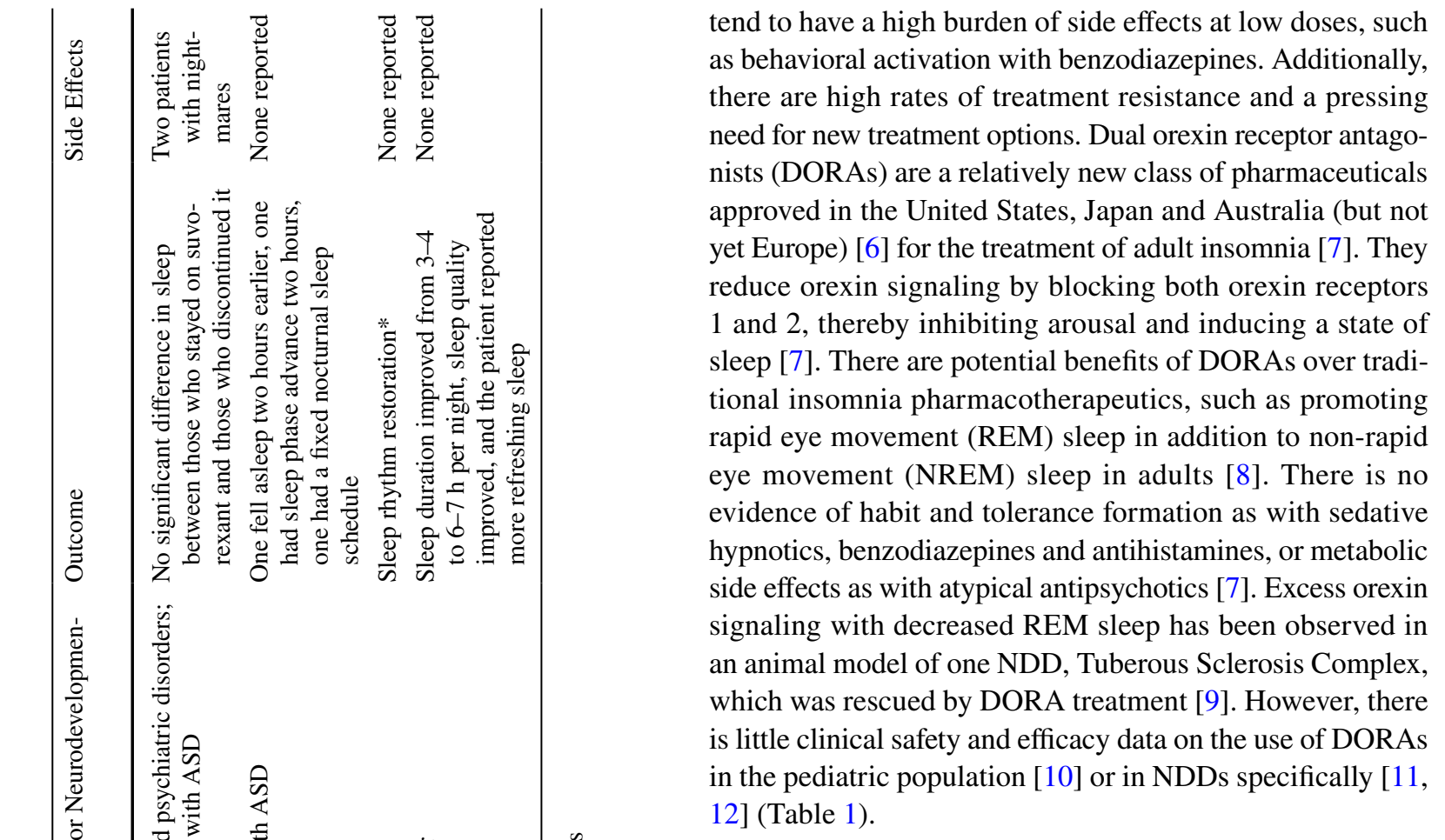

Methods

We share our experience using one DORA, suvorexant, in four patients with NDDs with clinically diagnosed insomnia who failed all other standard treatments. All patients and/ or guardians provided informed consent for publication of de-identified data (UCLA IRB 14-001908).

\section{Results}

Patient 1 was a 9-year-old female with Kleefstra Syndrome (Online Mendelian Inheritance in Man: 610253), ID, adrenal insufficiency, hypogammaglobulinemia, asthma, anismus, sleep maintenance insomnia, and obstructive sleep apnea. Her failed medication trials for insomnia included melatonin, trazodone, gabapentin, clonidine, guanfacine, cyproheptadine, and amitriptyline. We first started mirtazapine, which had little impact on her sleep and caused significant weight gain. We then started suvorexant $5 \mathrm{mg}$ nightly, which reduced the number of nighttime waking episodes. Its benefit for sleep maintenance dissipated over the course of several weeks, even on doses up to $15 \mathrm{mg}$ nightly, which was reached by titrating up by $5 \mathrm{mg}$ approximately once a month for 2 months. Based on a previous case series in Kleefstra Syndrome [13], we switched her to quetiapine $12.5 \mathrm{mg}$ nightly, with marked improvement in sleep maintenance.

Patient 2 was a 14-year-old male with asthma, ID, ASD, agitation and insomnia with sleep initiation insomnia. He 
had fragile $\mathrm{X}$ and chromosomal microarray testing at an outside institution, but the results were not available. He would stay awake until 5 am and then fall asleep for a few hours, having to then wake up for school. He was tired and irritable all day but could not fall asleep at bedtime. On intake, he was taking lorazepam $2 \mathrm{mg}$ nightly for anxiety and insomnia. He had previous failed trials of melatonin (agitation), fluoxetine and sertraline (mood disturbance, agitation, gastrointestinal upset). We started him on clonidine $0.1 \mathrm{mg}$ nightly and switched his lorazepam to clonazepam $0.25 \mathrm{mg}$ twice daily. His insomnia persisted and agitation worsened with clonidine, so it was stopped. He was titrated up to $75 \mathrm{mg}$ nightly of trazodone, with transient improvement in sleep initiation but ongoing difficulties with sleep maintenance. Suvorexant $5 \mathrm{mg}$ was added and titrated up to $15 \mathrm{mg}$ nightly by increasing the dose by $5 \mathrm{mg}$ per month over 2 months, with significant improvements in both sleep initiation and maintenance that has been sustained for over a year now without emergence of additional side effects.

Patient 3 was a 28 -year-old with ID, ASD, complex partial seizure disorder, bipolar disorder, aggressive behavior, obesity, and sleep initiation and maintenance insomnia. He was referred to medical genetics, but the outcome of that referral is undetermined. He had been tried on many psychotropic medications for behavior, epilepsy, and insomnia (full list unknown). He was stabilized on oxcarbazepine $300 \mathrm{mg}$ twice daily, lamotrigine $300 \mathrm{mg}$ twice daily, aripiprazole $10 \mathrm{mg}$ nightly, and clonidine $0.1 \mathrm{mg}$ nightly. His insomnia persisted, taking hours to fall asleep, and waking many times throughout the night. He was started on suvorexant $5 \mathrm{mg}$ and titrated up to $15 \mathrm{mg}$ over the course of several months. His sleep improved dramatically, falling asleep within $90 \mathrm{~min}$ and remaining asleep for $6-8 \mathrm{~h}$ per night. This was the best sleep he had "in years", per his mother. He subsequently lost more than 100 pounds due to increased daytime energy, his mood improved substantially, and he was able to attend an adult day program.

Patient 4 was a 13-year-old female with ASD, ID, epilepsy, obsessive-compulsive disorder, anxiety and insomnia. She had a normal chromosomal microarray, negative fragile $\mathrm{X}$ and $M E C P 2$ testing, and an autism gene panel revealed a maternally inherited (non-pathogenic) variant in NSDI. She had been tried on multiple psychotropics without significant benefit, including risperidone, clonidine, valproic acid, memantine, aripiprazole, and sertraline. On intake, she was on fluoxetine $5 \mathrm{mg}$ daily, quetiapine $75 \mathrm{mg}$ nightly and melatonin $6 \mathrm{mg}$ nightly. She continued to have poor sleep maintenance, so was trialed on suvorexant $5 \mathrm{mg}$ nightly without improvement or major side effects, so it was discontinued.

\section{Discussion}

We reported one male and three female patients with NDDs and insomnia who ranged in age from early childhood to early adulthood. They were all diagnosed with ID and all but one with ASD. They had a range of medical, neurological and psychiatric co-morbidities and one had a genetic diagnosis, Kleefstra Syndrome. Our patients had a range of responses to suvorexant, from dramatic and sustained improvement in sleep and quality of life (patient 3), to little to no benefit (patients 1 and 4). No major side effects were observed. In comparison, in an open-label study of suvorexant in thirty adolescents, no significant difference in sleep quality was seen at 6 months between the 17 patients on suvorexant compared to the 8 who completed the study but discontinued suvorexant [10]. The only side effect reported were nightmares in two patients. Seven of the patients had ASD, but no subgroup analysis was reported [10]. A case series of three adolescents with circadian rhythm sleep-wake disorders, two with ASD, reported subjective improvements in sleep schedules [11] and one youth with insomnia and bipolar disorder had improved sleep duration on $10 \mathrm{mg}$ of suvorexant [14]. In clinical trials of neurotypical adults with insomnia, suvorexant was associated with significant improvements in subjective time-to-sleep onset, total sleep time, and quality of sleep [15]. Participants reported elevated rates of somnolence, fatigue, abnormal dreams, and dry mouth [15].

These data suggest that suvorexant may be safe and effective for certain patients with NDDs, but additional research with prospective clinical trials in this specific population is necessary, especially in very young populations where the data are extremely sparse. Of note, the one patient of ours with a highly positive DORA response was a young adult (patient 3, age 28). Most trials in the general adult population used 20-40 mg [15], but we prescribed 5-15 mg out of caution, given the known sensitivity of patients with NDDs to psychotropic side effects. Additional caution is necessary with co-administration of CYP3A inhibitors, such as protease inhibitors or azole antifungals, as suvorexant is primarily eliminated through the CYP3A pathway [16]. Conversely, suvorexant may have reduced effectiveness in patients on CYP3A inducers, such as oxcarbazepine, carbamazepine, or phenytoin [16]. There are currently no biomarkers or clinical features predictive of DORA response, so clinical judgement must be used to select appropriate patients. Given established safety and effectiveness of other insomnia pharmacotherapeutics (Table 2), DORAs should only be considered for patients with NDDs who do not respond to or cannot tolerate all other established pharmacotherapeutics. There may be a genetic subpopulation of patients with NDDs who uniquely respond to suvorexant due to orexin 
Table 2 Pharmacotherapeutic options for insomnia in patients with neurodevelopmental disorders

\begin{tabular}{|c|c|c|c|}
\hline Class of Medication & Example Medications & Potential benefits for patients with NDDs & Potential concerns for patients with NDDs \\
\hline Exogenous Hormone & Melatonin & $\begin{array}{l}\text { Available over the counter with robust } \\
\text { safety and efficacy data in pediatric and } \\
\text { NDD populations }\end{array}$ & $\begin{array}{l}\text { No long-term data on impact of neurodevel- } \\
\text { opment }\end{array}$ \\
\hline Melatonin Agonists & $\begin{array}{l}\text { Ramelteon } \\
\text { Tasimelteon }\end{array}$ & $\begin{array}{l}\text { Relatively safe with few side effects, longer } \\
\text { acting-than melatonin. Ideal for patients } \\
\text { with non-24-h sleep-wake disorder }\end{array}$ & $\begin{array}{l}\text { Relatively little data in pediatric and NDD } \\
\text { populations }\end{array}$ \\
\hline Alpha-agonists & $\begin{array}{l}\text { Clonidine } \\
\text { Guanfacine }\end{array}$ & $\begin{array}{l}\text { Ideal for patients with comorbid ADHD, } \\
\text { tics, or irritability }\end{array}$ & $\begin{array}{l}\text { Generally well tolerated. Small risk of } \\
\text { anticholinergic side effects and hypoten- } \\
\text { sion, dizziness and syncope }\end{array}$ \\
\hline Antihistamines & $\begin{array}{l}\text { Diphenhydramine } \\
\text { Hydroxyzine }\end{array}$ & $\begin{array}{l}\text { Ideal for brief, occasional insomnia. } \\
\text { Diphenhydramine is available over the } \\
\text { counter }\end{array}$ & $\begin{array}{l}\text { Risk of paradoxical disinhibition, anticho- } \\
\text { linergic side effects, and development of } \\
\text { tolerance }\end{array}$ \\
\hline $\begin{array}{l}\text { Non-benzodiazepine Seda- } \\
\text { tive Hypnotics }\end{array}$ & $\begin{array}{l}\text { Zolpidem } \\
\text { Zaleplon } \\
\text { Eszopiclone }\end{array}$ & $\begin{array}{l}\text { Generally contraindicated in patients with } \\
\text { NDDs because of high risk of paradoxical } \\
\text { response }\end{array}$ & $\begin{array}{l}\text { Very limited data in pediatric populations, } \\
\text { risk of disinhibition, parasomnias and } \\
\text { hallucinations }\end{array}$ \\
\hline Benzodiazepines & $\begin{array}{l}\text { Lorazepam } \\
\text { Tenazepam } \\
\text { Clonazepam }\end{array}$ & $\begin{array}{l}\text { Ideal for patients with comorbid parasom- } \\
\text { nias or panic disorders }\end{array}$ & $\begin{array}{l}\text { High risk of paradoxical responses, risk of } \\
\text { developing tolerance, can be habit form- } \\
\text { ing, takes time to taper safely }\end{array}$ \\
\hline Tricyclic Antidepressants & $\begin{array}{l}\text { Amitriptyline } \\
\text { Doxepin }\end{array}$ & $\begin{array}{l}\text { Ideal for patients with comorbid depres- } \\
\text { sion, anxiety, or functional gastrointestinal } \\
\text { disorders }\end{array}$ & $\begin{array}{l}\text { Limited data in pediatric and NDD popula- } \\
\text { tions. High risk of anticholinergic side } \\
\text { effects, sexual dysfunction, increased } \\
\text { suicidality in children, adolescents and } \\
\text { young adults }\end{array}$ \\
\hline Tetracyclic Antidepressants & Mirtazapine & $\begin{array}{l}\text { Ideal for patients with comorbid depres- } \\
\text { sion, anxiety, or functional gastrointestinal } \\
\text { disorders }\end{array}$ & $\begin{array}{l}\text { May cause moderate weight gain, risk of } \\
\text { mania with bipolar disorder, increased } \\
\text { suicidality in children, adolescents and } \\
\text { young adults }\end{array}$ \\
\hline Atypical Antipsychotics & $\begin{array}{l}\text { Quetiapine } \\
\text { Olanzapine }\end{array}$ & $\begin{array}{l}\text { Ideal for patients with comorbid agitation/ } \\
\text { aggression, psychosis, or bipolar disorder }\end{array}$ & $\begin{array}{l}\text { Significant metabolic side effects, risk of } \\
\text { extrapyramidal symptoms and lowering of } \\
\text { seizure threshold }\end{array}$ \\
\hline Gabapentinoids & $\begin{array}{l}\text { Gabapentin } \\
\text { Pregabalin }\end{array}$ & $\begin{array}{l}\text { Ideal for patients with comorbid pain } \\
\text { disorders, anxiety disorders, or epilepsy. } \\
\text { Relatively safe }\end{array}$ & $\begin{array}{l}\text { Limited safety and efficacy data in pediatric } \\
\text { and NDD populations }\end{array}$ \\
\hline
\end{tabular}

$A D H D$ attention-deficit hyperactivity disorder, $N D D$ neurodevelopmental disorder

signaling dysfunction, such as tuberous sclerosis complex [9], but this has yet to be confirmed. There is precedent for genetic diagnoses guiding sleep management. Patients with Smith-Magenis Syndrome have an inverted melatonin circadian rhythm that can be corrected through suppression of morning endogenous melatonin with beta blockers and evening supplementation with exogenous melatonin [17]. Thus, a gene-first approach may allow for the identification of DORA-responsive patients in the future.

In conclusion, our four patients with NDDs and insomnia had variable but promising responses to treatment with suvorexant. The use of DORAs in patients with NDDs must be approached with caution given the lack of current safety and efficacy data in pediatric and NDD populations. Off-label use may be appropriate in cases when no established treatment works if caution is used and side effects are closely monitored, but this needs to be studied further. Specifically, clinicians should discuss the limitations to our current knowledge base about the effects of suvorexant on children with NDDs (as no rigorous clinical trials have been completed), the known side effects from studies of other populations (e.g., abnormal dreams, daytime drowsiness, dry mouth), the possibility of paradoxical or unknown side effects, and the importance of starting at low doses and titrating slowly to find the minimal effective dose. One limitation to our study was that our patients did not have specialized sleep evaluations that included polysomnography or actigraphy. Insomnia diagnoses were made based on clinical history, reflective of the common clinical situation most providers are faced with when treating sleep disorders in patients with NDDs. However, in future clinical studies to establish safety and efficacy and to identify predictors of DORA response in patients with NDDs, a more formalized sleep assessment will be beneficial to establish a definitive insomnia diagnosis and assure a more homogeneous study population. 
Acknowledgements The authors would like to thank their colleagues in the UCLA CARING Clinic for all their conversations, advice, support, and guidance. This work was supported by the UCLA Savant Fellowship in Developmental Neurogenetics (ADB) and by the National Institute of General Medical Sciences (2T32GM008243-3, ADB).

\section{Declarations}

Conflict of interest Aaron D. Besterman has no conflicts of interest to disclose. Shafali S. Jeste served as a consultant for Roche Pharmaceuticals and on the professional advisory board for the Tuberous Sclerosis Alliance. All drafts of this manuscript were fully written and prepared by the study authors.

Open Access This article is licensed under a Creative Commons Attribution 4.0 International License, which permits use, sharing, adaptation, distribution and reproduction in any medium or format, as long as you give appropriate credit to the original author(s) and the source, provide a link to the Creative Commons licence, and indicate if changes were made. The images or other third party material in this article are included in the article's Creative Commons licence, unless indicated otherwise in a credit line to the material. If material is not included in the article's Creative Commons licence and your intended use is not permitted by statutory regulation or exceeds the permitted use, you will need to obtain permission directly from the copyright holder. To view a copy of this licence, visit http://creativecommons.org/licenses/by/4.0/.

\section{References}

1. Surtees ADR, Oliver C, Jones CA et al (2018) Sleep duration and sleep quality in people with and without intellectual disability: a meta-analysis. Sleep Med Rev 40:135-150. https://doi.org/10. 1016/j.smrv.2017.11.003

2. Sateia MJ (2014) International classification of sleep disordersthird edition highlights and modifications. Chest 146:1387-1394. https://doi.org/10.1378/chest.14-0970

3. Blackmer AB, Feinstein JA (2016) Management of sleep disorders in children with neurodevelopmental disorders: a review. Pharmacotherapy 36:84-98

4. Bruni O, Angriman M, Melegari MG, Ferri R (2019) Pharmacotherapeutic management of sleep disorders in children with neurodevelopmental disorders. Expert Opin Pharmacother 20:2257-2271

5. Abdelgadir IS, Gordon MA, Akobeng AK (2018) Melatonin for the management of sleep problems in children with neurodevelopmental disorders: a systematic review and metaanalysis. Arch Dis Child 103:1155-1162. https://doi.org/10.1136/ archdischild-2017-314181

6. Gray A (2019) Before the dawn: the tough regulatory climate holding back insomnia relief. Pharm J. https://doi.org/10.1211/ pj.2019.20207351

7. Janto K, Prichard JR, Pusalavidyasagar S (2018) An update on dual orexin receptor antagonists and their potential role in insomnia therapeutics. J Clin Sleep Med 14:1399-1408. https://doi.org/ $10.5664 /$ jcsm. 7282

8. Clark JW, Brian ML, Drummond SPA, et al (2020) Effects of orexin receptor antagonism on human sleep architecture: a systematic review. Sleep Med Rev 53

9. Zhang B, Guo D, Han L et al (2020) Hypothalamic orexin and mechanistic target of rapamycin activation mediate sleep dysfunction in a mouse model of tuberous sclerosis complex. Neurobiol Dis. https://doi.org/10.1016/j.nbd.2019.104615

10. Kawabe K, Horiuchi F, Ochi M et al (2017) Suvorexant for the treatment of insomnia in adolescents. J Child Adolesc Psychopharmacol 27:792-795. https://doi.org/10.1089/cap.2016.0206

11. Oka Y, Tanno S, Kawasaki Y et al (2017) Dual orexin receptor antagonist for the treatment of circadian rhythm sleep-wake disorders. J Neurol Sci 381:297. https://doi.org/10.1016/j.jns.2017. 08.844

12. Iwata M, Kaneko K (2020) Non-24-hour sleep-wake disorder successfully treated with the combination of ramelteon and suvorexant in a case of autism spectrum disorder. Neuropsychopharmacol Reports 40:383-387. https://doi.org/10.1002/npr2.12142

13. Vermeulen K, Staal WG, Janzing JG et al (2017) Sleep disturbance as a precursor of severe regression in kleefstra syndrome suggests a need for firm and rapid pharmacological treatment. Clin Neuropharmacol 40:185-188. https://doi.org/10.1097/WNF.0000000000 000226

14. Prieto DI, Zehgeer AA, Connor DF (2019) Use of suvorexant for sleep regulation in an adolescent with early-onset bipolar disorder. J Child Adolesc Psychopharmacol 29:395. https://doi.org/10. 1089/cap.2019.0029

15. Kuriyama A, Tabata $H$ (2017) Suvorexant for the treatment of primary insomnia: a systematic review and meta-analysis. Sleep Med Rev 35:1-7

16. Merck Sharp \& Dohme Corp (2014) BELSOMRA Prescribing Information

17. De Leersnyder H, de Blois MC, Vekemans M et al (2001) beta(1)adrenergic antagonists improve sleep and behavioural disturbances in a circadian disorder, Smith-Magenis syndrome. J Med Genet 38:586-590. https://doi.org/10.1136/jmg.38.9.586 